\title{
Rejuvenating the Cider Route in Quebec: An Action Design Research Approach to Stakeholder Collaboration and Innovation
}

\author{
L. Martin Cloutier, Laurent Renard, \\ Sébastien Arcand, and E. Michael Laviolette
}

\author{
"Our goals can only be reached through $a$ ") \\ vehicle of a plan, in which we must fervently \\ believe, and upon which we must vigorously \\ act. There is no other route to success.
}

Pablo Picasso (1881-1973)

Artist, poet, and playwright

\begin{abstract}
This article examines the problem of rejuvenating collaboration for innovation among cideries (cider producers) and the regional tourism association as the historical key stakeholders of the Cider Route of the Montérégie region in Quebec, Canada. The article reports on the initial steps of an action design research approach to support the stakeholders of the Cider Route in designing an innovative solution in response to numerous challenges they face, including a lack of new initiatives and steeply declining membership among cideries. The first step of the action design research was to define the problem: to renew the collaborative process among the Cider Route stakeholders by redefining the vision, mission, and strategy leading to an artifact proposal that could take the form of a mobile application. Thus, the notion of a boundary object is employed - in relation to the process of designing an information technology artifact in the form of a mobile application for the Cider Route - as a way to understand the need to collaborate to innovate in this context. The article also reports on the ongoing second step of the action design research process, which consists of supporting the collaborative process using group concept mapping. The group concept mapping method was suggested to guide and sustain the collaborative process over time because it is a participatory, bottom-up, mixed-methods approach to evaluation and planning. The group concept mapping, applied within the action design research approach, could be helpful in two ways: first, to define the rejuvenated vision, mission, and strategy for the Cider Route; second, to define the specific functionalities of the mobile application for the Cider Route.
\end{abstract}

\section{Introduction}

A substantial amount of research has been conducted on wine routes and oenotourism (Brunori \& Rossi, 2000; Correia et al., 2004; Hashimoto \& Telfer, 2008; López Guzmán et al., 2014; Rainer, 2016; Telfer, 2001). In particular, the strategic potential of theme trails and routes to contribute to the development of tourism and regions across the world has been widely investigated (Peris-Ortiz et al., 2016). However, there appears to be no prior research on cider routes in spite of the growing interest for cider transformation and consumption in Quebec and elsewhere (Jolicoeur, 2013). This article examines how an action design research approach to the design and development of the artifact proposal (a mobile application), to be considered as a boundary object, can help foster both collaboration and innovation among stakeholders of the Cider Route in Quebec, Canada (Box 1; Figure 1). 


\section{Rejuvenating the Cider Route in Quebec: An Action Design Research Approach}

\section{Martin Cloutier, Laurent Renard, Sébastien Arcand, and E. Michael Laviolette}

\section{Box 1. Quebec's Cider Route}

The Cider Route (or Route des cidres, in French) is located in the Montérégie region of southwestern Quebec, Canada. The region takes its name from the isolated Monteregian Hills, which are situated between the Laurentian and Appalachian mountain ranges, and provide a scenic backdrop to the region's orchards and cideries. Nearly 1.5 million people live in the region's $11,000 \mathrm{~km} 2$ land area, which features a mix of urban and rural areas. Agriculture and tourism provide the foundation of the region's economy.

The "terroir" of the region is particularly well suited to growing apples, and cider production has long been a part of the region's history. The cideries usually consist of small cider houses, or mills, located alongside the apple orchards. The various cideries produce a wide variety of unique, craft apple ciders (including sweet, dry, still, and sparkling), ice ciders, and apple spirits.
The Cider Route was established in 1998 in the course of implementing the Montérégie region's agrotourism strategy, so that it could help fulfill stakeholder's joint region's mission and vision: attract and extend visitors' stays in the region, establish the brand recognition of the craft cider makers, and grow sales volume of

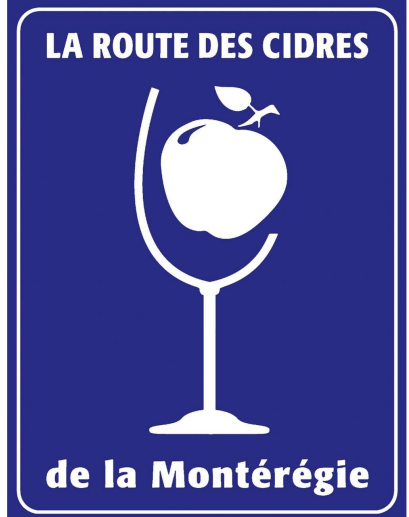

Image credit: Tourisme Montérégie cider in that nascent industry at the time. The exact route can vary depending on which cideries participate in a given year, but it is designed to take visitors through key scenic, historical, and culinary landmarks in the region as they travel from cidery to cidery.

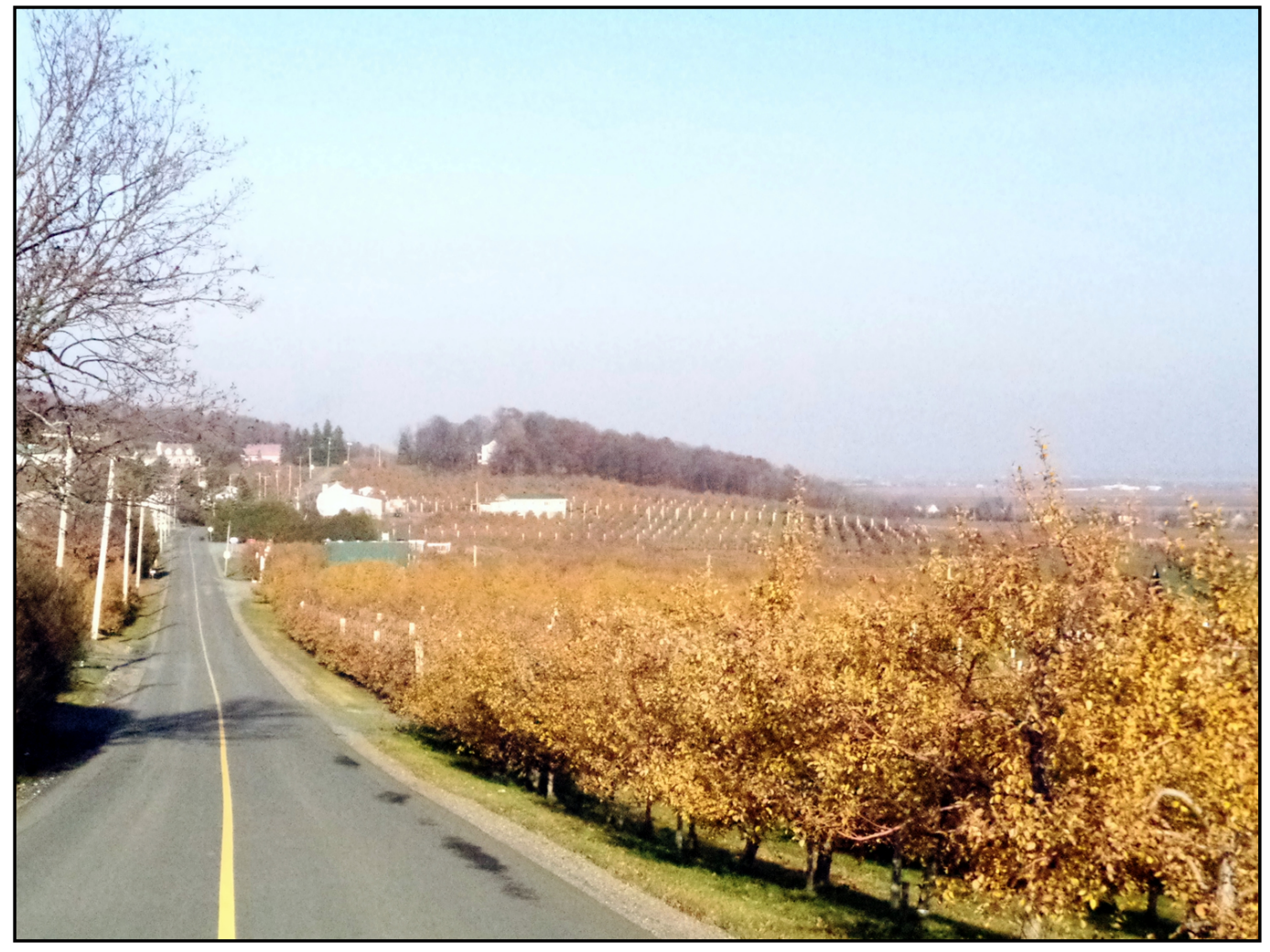

Figure 1. A visitor's view of the scenic Cider Route 


\section{Rejuvenating the Cider Route in Quebec: An Action Design Research Approach}

\section{Martin Cloutier, Laurent Renard, Sébastien Arcand, and E. Michael Laviolette}

For the tourism industry, a theme trail makes it possible to organize product offers around a path, a route, or a trail to ensure tourism development and hence the economic development of a given region. If we consider the desirable characteristics of an agrotourism route, it must be anchored in a given territory and it ought to allow visitors to follow a path so they can enjoy a worthwhile experience and journey (Dumoulin, 2003).

The attractiveness of a theme route is typically the result of individual and collective stakeholders' joint efforts. In the particular case examined here, these stakeholders include participating cideries and the regional tourism association (Tourisme Montérégie; tourisme-monteregie.qc.ca/en). For the Cider Route, individual and collective efforts are associated with: i) the definition of a portfolio of quality experiences at the cideries; ii) enjoyable scenery, service infrastructure, and road signs along the route; and iii) relevant and appropriate marketing and promotion. In other words, stakeholders must work hand in hand to ensure that the theme trail is a success (Brunori \& Rossi, 2000).

Many researchers have emphasized the frequent lack of collaboration among stakeholders involved in agrotourism trails and routes; in fact, it appears to be a ubiquitous problem in these types of collective efforts that involve multiple stakeholders (Brás et al., 2010; Brunori \& Rossi, 2000). This problem also appears to be severe given that it represents a major obstacle to the feasibility of actions proposed to enhance the desirable evolving features of theme trails in general. As will be detailed below in the article, the challenges facing the Cider Route in Quebec are quite typical of what has been highlighted in the literature on agrotourism trails. Indeed, the current situation regarding the relationship among the stakeholders of the Cider Route is such that the traditional joint initiative or annual event could not be held or undertaken over the past two seasons. As a result, the situation has turned into a vicious cycle for which the lack of dynamism has led to low levels of membership as to threaten the very existence of the Cider Route.

Hence, the fundamental question raised in this article is: How is it possible to ensure that a theme trail's stakeholders (e.g., the cider makers and the regional tourism association) can collaborate to innovate, given that they may not necessarily have the same underlying interests, and that they may hold contrasting business objectives, which translates into difficulties working together? As will be seen, there are indeed many issues hindering collaboration between the main stakeholders of the Cider Route. That lack of collaboration substantially limits the innovative capability of stakeholders to contribute to the Cider Route's much-needed rejuvenation.

To address the collaboration issue among the stakeholders of the Cider Route, we applied the design science research paradigm. This paradigm belongs to the science of the artificial (Avenier, 2010; Simon, 1996), and serves to achieve a double objective: i) establish a process for organizational innovation; and ii) allow knowledge creation (Gregor \& Hevner, 2013). Within the design science paradigm, the action design research approach (Sein et al., 2011) was precisely employed to support the collaborative innovation effort work process of all stakeholders involved, and the creation of the artifact proposal (i.e., the mobile application). The artifact proposal emerges from the interaction within the organizational context at the onset of the action design approach guided by the researchers' intent. The action design research approach helps conceptualize the research process which contains the inseparable and inherently interwoven set of activities required to build an IT artifact, to intervene within the organization, and to evaluate it iteratively and synchronously within feedback loops.

The action design research approach was selected for the following reasons. First, it is a notion that is widely used in the information technology/information systems literature, and it seeks to be relevant to the stakeholders' needs by responding to contextualized problem imperatives defined in collaboration. Second, it strives to be rigorous in process and outcome by conceptualizing, developing, and evaluating both the intermediate non-IT and the ultimate IT artifacts designed to solve the problem at hand. An IT artifact is a bundle of "material and cultural properties packaged in some socially recognizable form such as hardware and/or software" (Orlikowski \& Iacono, 2001). The reason for adopting the action design approach as presented in this article is also based on the notion that IT artifacts developed as part of an action design research process can play a prominent role in improving a tourism experience, especially when available as mobile applications (Neuhofer et al., 2015; Wang et al., 2012; Wang et al., 2016).

The scope of this article covers the realization of Step 1 (problem formulation), and proposes a methodological framework for Step 2 (building, intervention, and evaluation) of the overall action design approach. Given the 


\section{Rejuvenating the Cider Route in Quebec: An Action Design Research Approach}

\section{Martin Cloutier, Laurent Renard, Sébastien Arcand, and E. Michael Laviolette}

diagnosis of the problem affecting the Cider Route, which we documented as part of Step 1 with the involvement of existing stakeholders, it became apparent that the design and development of a mobile application was crucial for the future of the Cider Route. In other words, the creation of a virtual Cider Route using an innovation, such as designing and building a mobile application, could lead to the long-term survival of the actual Cider Route!

Thus, the methodological framework proposed through Step 2 (building, intervention, and evaluation) is the essential contribution of this article, for four reasons. First, considering the design and development of a mobile application as a boundary object (Star \& Griesemer, 1989) would entice stakeholders to innovate through collaboration (Worley et al., 2010). Second, the design and development of the application require the intermediate step of building a well-crafted mission, vision, and strategy. Third, a well-designed mobile application stemming from the Cider Route's mission, vision, and strategy would meet visitors' needs for a quality planning and guidance tool that would help them plan a visit to participating cideries. Fourth, this intervention process essentially provides occasions for joint actions and interactions that support routine development collaborations among stakeholders.

Thus far, no mobile application for the Cider Route exists, although similar mobile applications are available for cider and wine routes elsewhere, such as mobile applications for La comarca de la sidra, in Spain (tinyurl.com/gm268t8) and a geographic information system for Bordeaux wines, in France (tinyurl.com/jgph99s).

The remainder of the article is structured as follows. The next section focuses on describing the basic fundamentals of action design research: in particular, what it consists of and what steps are involved. Then, we report on the outcomes from Step 1 (problem formulation) and Step 2 (building, intervention, and evaluation). Our discussion then documents the process recommended to design the Cider Route's artifact proposal. Finally, we offer conclusions.

\section{Action Design Research: Methodological Fundamentals}

This section introduces the basic notions of design science research and justifies its relevance and relation- ship to the action design research approach. Then, it introduces and outlines the research steps suggested by the action design research approach. In addition, it introduces the notion of a boundary object more formally, in order to motivate the use of an action design research approach as a means to foster collaboration for innovation in the tourism industry.

\section{Action design research: A primer}

Many different design science research approaches and implementation steps have been proposed by various researchers (Hevner \& Chatterjee, 2010; Johannesson \& Perjons, 2014; Peffers et al., 2007; Takeda et al., 1990). They consist of a set of steps and guidelines to be followed, and they are typically articulated around problem definition, conception, artifact development, implementation, and evaluation in context. However, Sein and colleagues (2011) insist that all these alternative design science research approaches neglect the key element in the success of the process: the organization or context within which the intervention takes place. And, the joint action of all stakeholders involved in the process contributes in one way or another to the design, development, and evaluation of the artifact: this is a joint effort! Action design research is a significant improvement when the end goal of the intervention process is to help an organization. That is why design science research is helpful in these collective and participatory processes; the action design research approach involves "(1) addressing a problem situation encountered in a specific organizational setting by intervening and evaluating; and (2) constructing and evaluating an IT artifact that addresses the class of problems typified by the encountered situation" (Sein et al., 2011).

Relevance and rigour are both key tenets of design science research that must be applied to the design, development, and evaluation of IT artifacts. IT artifacts must provide a satisfactory answer to contextual problems, while simultaneously being based on recognized scientific knowledge, research methods, and techniques. IT artifacts as research outcomes are often considered to be final artifacts. As solutions to practical organizational problems, they can take the form of constructs, models, methods, and instantiations (March \& Smith, 1995) or design theories (Gregor \& Jones, 2007). Nevertheless, it is important to note that intermediate artifacts are often produced at the various research steps (van Aken, 2005), and they form an invaluable set of critical artifacts toward the end goal. 


\section{Rejuvenating the Cider Route in Quebec: An Action Design Research Approach}

\section{Martin Cloutier, Laurent Renard, Sébastien Arcand, and E. Michael Laviolette}

Action design research: The steps

The action design research process is a four-step process: i) problem formulation; ii) building, intervening, and evaluating; iii) reflecting and learning; and iv) formalization of learning (Figure 2). Problem formulation is the first step and it ensures that the problem is defined and integrated within an organizational context based on an examination shared by the researchers and the stakeholders. The second step includes processes of building, intervening, and evaluating, which are executed iteratively and continuously as the IT artifact is designed, developed, integrated, and evaluated within the host organization. The third step involves reflecting on and learning from the previous two steps. The objective is to obtain a theoretical construction from the iterations conducted at the first and second steps and leading to the final IT artifact, in order to elicit conscious theoretical knowledge. The fourth step concerns the formalization of learning points and lessons learned throughout the research process. This final step strives to formalize the knowledge produced from the IT artifact that was generated and to develop it so that a solution or a process, as the case may be, can subsequently be applied to other classes of analogous problems.

For each step shown in Figure 2, it is most likely necessary to use specific methods to collect and analyze data to define the production and analysis framework that meets both internal and external validity criteria. Thus, work conducted using the action design research ap- proach may be based on different data collection and analysis methods, on the one hand, and may also be based on a coherent epistemological paradigm with specific theories or notions, on the other hand. While recognizing that conceptual, theoretical, and empirical frameworks may differ between steps, it is important to retain methodological consistency within each step. As such, it is possible to design an action design research process composed of sub-research steps articulated around the four basic steps.

Non-IT and IT artifacts as boundary objects:

Collaboration for innovation in tourism

Boundary objects (Star \& Griesemer, 1989) support collaboration between different stakeholders, social worlds (Strauss, 1978), or communities of practice (Carlile, 2002). Boundary objects are translation processes that can ensure coordination, cohesion, and collaboration in groups. They help establish a "shared syntax or language for individuals to represent their knowledge" (Carlile, 2002). "An effective boundary object at a semantic boundary provides a concrete means for individuals to specify and learn about their differences and dependencies across a given boundary" and it "facilitates a process where individuals can jointly transform their knowledge" (Carlile, 2002).

Boundary objects are sufficiently flexible to adapt to the local, constraining needs of stakeholders who will be using them and to maintain a certain collective unity.

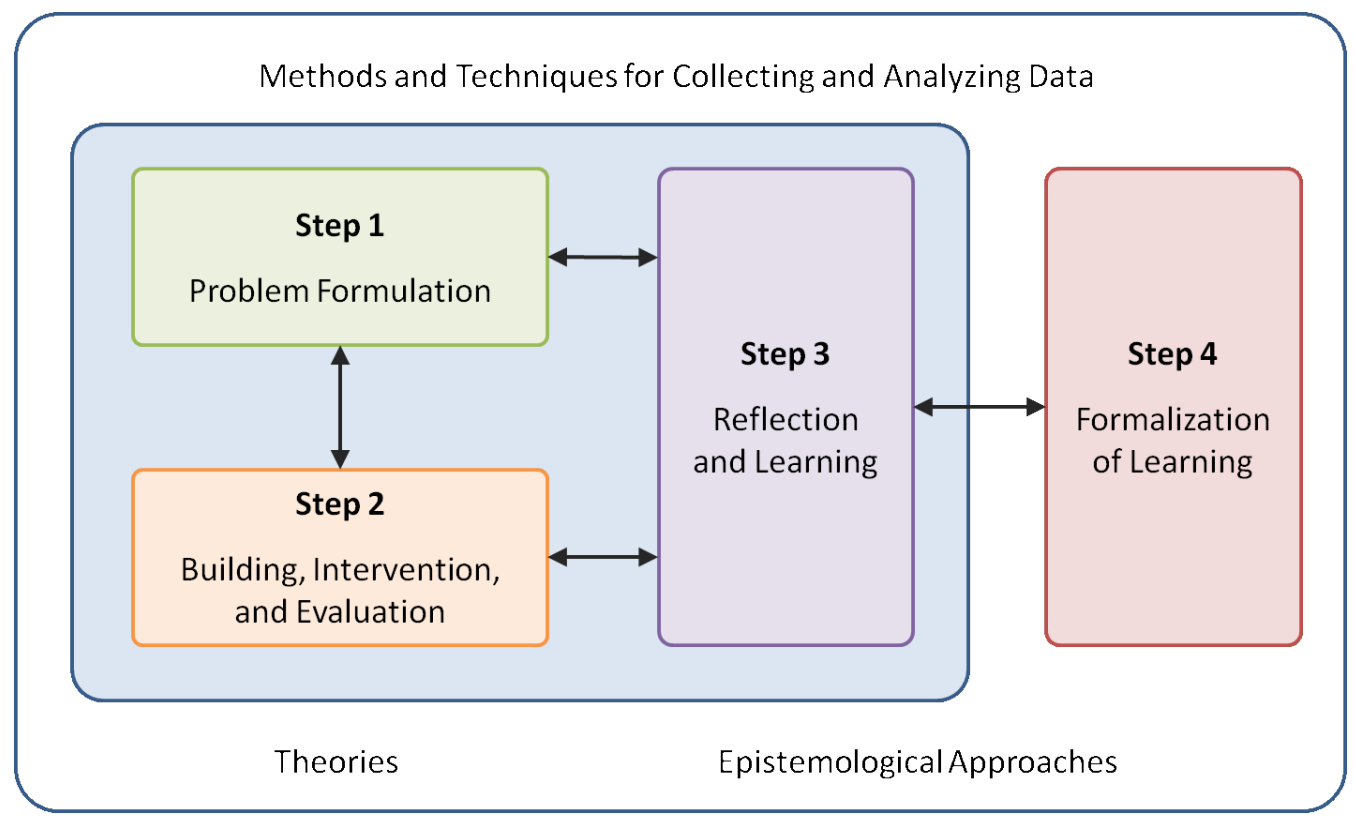

Figure 2. The action design research method framework (adapted from Sein et al., 2011) 


\section{Rejuvenating the Cider Route in Quebec: An Action Design Research Approach}

\section{Martin Cloutier, Laurent Renard, Sébastien Arcand, and E. Michael Laviolette}

These objects can be artifacts in various forms: concrete, abstract, or both at the same time as on a continuum. "Their boundary nature is reflected by the fact that they are simultaneously concrete and abstract, specific and general, conventionalized and customized" (Star \& Griesemer, 1989). Boundary objects have been examined in various contexts within different types of projects (Iorio \& Taylor, 2014), such as in the study of virtual projects (Iorio \& Taylor, 2014) and participatory IT process design (Rasmussen et al., 2013). Moreover, boundary objects can also exhibit specific properties such as being "conflict process mediators" (Iorio \& Taylor, 2014). Boundary objects can be intermediary and final artifacts produced during or as an outcome of the research process. Moreover, considering intermediary or final artifacts as boundary objects consists of attributing them specific properties, as they were introduced above, because they are central to the collaborative process. They are boundary objects because they are both the process that initiates the collaboration and an output from it.

\section{Step 1. Problem Formulation: Identifying Challenges Facing the Cider Route}

This section includes three parts: first, the context of the Cider Route is briefly outlined; then, the evaluation process is described; finally, some key lessons or challenges are presented to justify the treatment of the IT artifact as a boundary object in order to foster collaboration among the stakeholders of the Cider Route.

\section{Context of the Cider Route}

As the map in Figure 3 shows, the distance from the southwestern to the northeastern section of the Montérégie region spans over 200 kilometres. The Cider Route itself follows about 120 kilometres of road from end to end. The Cider Route has never been a permanent geographic fixture; that is, its route tends to evolve and change based on the location of the cideries that participate in the regional tourism association's annual launch event. This changing nature can be seen in the two very different routes used in 2013 and 2016

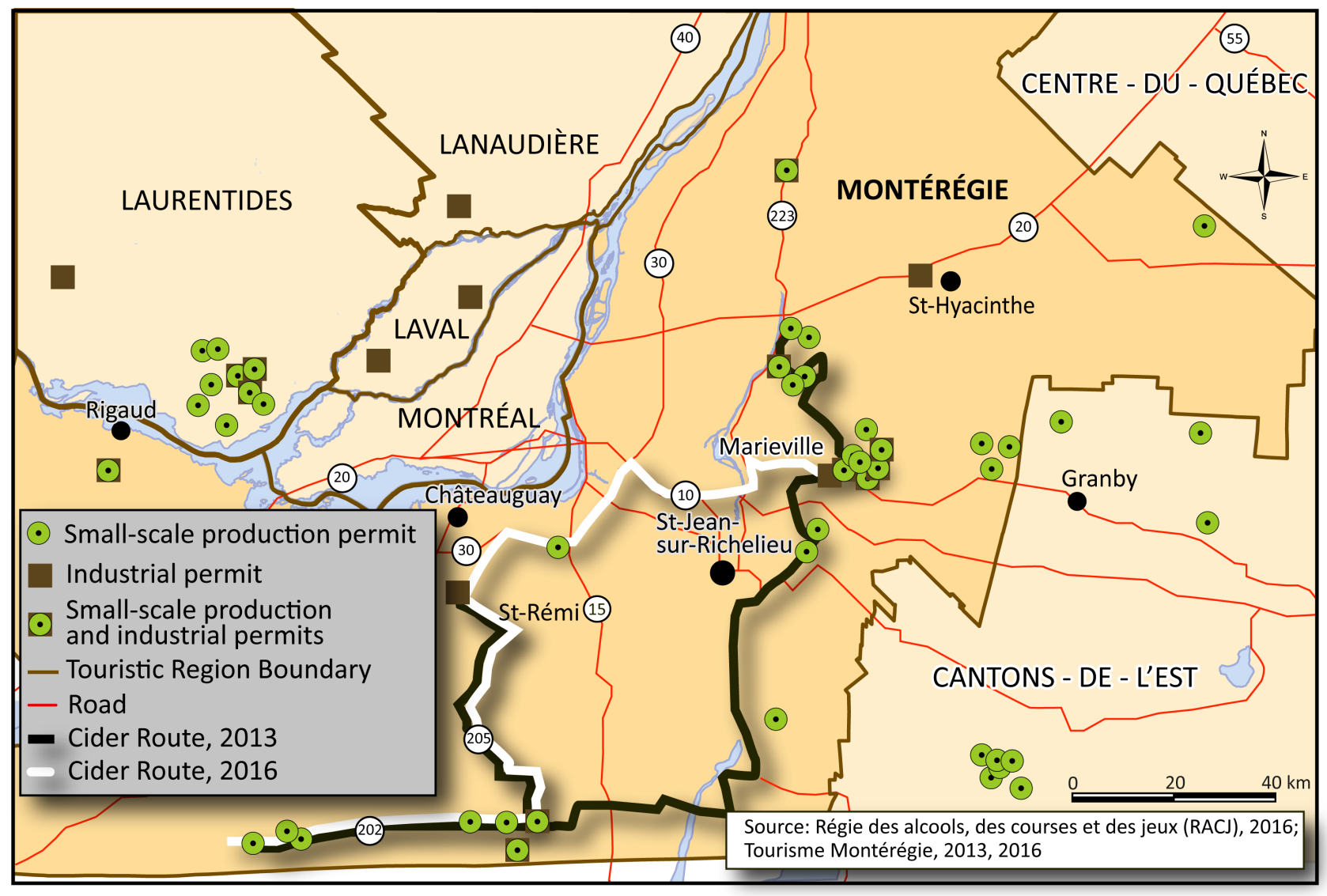

Figure 3. Map of the Cider Route showing the participating cideries and routes used in 2013 and 2016. (Cartography by Yann Roche and Mourad Djaballah, 2016) 


\section{Rejuvenating the Cider Route in Quebec: An Action Design Research Approach}

\section{Martin Cloutier, Laurent Renard, Sébastien Arcand, and E. Michael Laviolette}

(Figure 3). Furthermore, one of the most important characteristics of the Cider Route is that it has never been integrated with the official road signage program for theme routes or trails established by Quebec's departments of Transport and Tourism because it does not meet certain criteria (e.g., the route overlaps with other officially recognized roads or trails or circuits, which is not allowed). For the cideries, the consequence is that the signs indicating their participation in the Cider Route can only be installed on their own property and not in the public space along the side of the road. Obviously, this restricts the visibility of the road signs, and hence of the Cider Route itself, quite substantially.

\section{Methodological framework}

As part of Step 1 in action design research - that is, addressing a problem situation - nine semi-directed interviews about 90 minutes long were conducted as part of a first round of interviews with stakeholders of the Cider Route (i.e., cider makers, representatives from the regional tourism association, and visitors). Secondary data were also collected (e.g., Cider Route roadmaps, web traffic data, debriefing memos of meetings held between the cider makers and the regional tourism association). The contents of the first round of interviews were analyzed using inductive inferencing. With a basic coding scheme, the information contents that emerged from that process provided materials to document the problem, that is: i) what the Cider Route is; ii) what the Cider Route does; and iii) what the Cider Route is becoming (based on the systemic framework of Le Moigne, 1994). The coding scheme based on these dimensions made it possible to reveal tensions between the stakeholders of the Cider Route and to suggest a diagnosis of the situation. The results obtained were presented and debriefed during a second round of three interviews with some of the stakeholders who had been interviewed in order to meet external validity criteria.

\section{Key findings}

The results of the work conducted with participating cideries and visitors of the Cider Route led to the conclusion that the Cider Route is faltering, as far as the cider makers' involvement is concerned, due to a decline in membership. Indeed, although the number of craft cideries with small-scale production permits in the region has grown, and they are operated by cider makers who are association members of The Artisans Cider Producers of Quebec (cidreduquebec.com/association-en.html), the number of Cider Route members has steadily declined over the past few years. Reasons cited include a perception of insufficient benefits from remaining a member of the route, the declining involvement of the regional tourism association in developing the route, and competing tourism alternatives for selling their products. The situation is such that many current stakeholders fear the Cider Route may be discontinued if membership dwindles to such a small number that there would be too few destinations to maintain a viable "route". However, both Cider Route members and representatives of the regional tourism association expressed a need to "shock the system" with a meaningful initiative in an effort to rejuvenate the Cider Route.

In addition, a few other challenges were identified. First, the Cider Route's governance should be reconsidered. The Cider Route is not owned by any of the stakeholders currently involved in its management the cider makers and the regional tourism association although it is jointly financed by both groups. However, a well-defined governance structure should clearly establish the leadership position and specify the roles and responsibilities of each stakeholder. Such changes would have a major impact on the capability-building process required to define a clear and coherent vision, mission, and strategy for the Cider Route.

Second, other Cider Route stakeholders, such as visitors, bloggers, sommeliers, tour organizers, and the like, have not historically taken part in the conversation between cider makers and the regional tourism association. It is vital to involve all potential stakeholders (including visitors, bloggers, sommeliers, and tour operators) in the process of defining a common product strategy to ensure proper project leadership and ownership (Smith et al., 2010). The process of defining a Cider Route vision, mission, and strategy would minimally include actions such as: i) mapping out the roles and responsibilities of all stakeholders; ii) identifying the actions of interest to be undertaken by all stakeholders; iii) conducting research work on the needs, expectations, values, and impact of all stakeholders; and iv) engaging all stakeholders in a process leading to a meaningful outcome (Smith et al., 2010).

Third, there is a challenge related to the lack of metrics about the Cider Route, such as: i) the number of visitors; ii) the experience or satisfaction of visitors; and iii) the Cider Route's economic impact on the region. For example, the visitor experience offered at the different cideries along the Cider Route has been described during interviews conducted with participants as "uneven", yet there are no metrics related to the measurement of the customer experience along the route. As a consequence, it is difficult to measure the economic impact of the Cider Route on the cideries, 


\section{Rejuvenating the Cider Route in Quebec: An Action Design Research Approach}

\section{Martin Cloutier, Laurent Renard, Sébastien Arcand, and E. Michael Laviolette}

and more broadly on the region itself. As such, it becomes increasingly difficult to justify further investment without these metrics readily available to decision makers.

A fourth challenge relates to the uneven quality of existing artifacts for the Cider Route, including the design of websites for the cideries and the regional tourism association. The cideries websites are often criticized by visitors or tourists because of poor organization and a lack of practical information. The association's website is also problematic because it only includes a single map showing all the different trails and circuits that visitors can take in the entire region. For visitors interested in planning a journey focused on the Cider Route, the general map is more confusing than helpful.

\section{Step 2. Artifact Building, Intervention, and Evaluation: A Mobile Application for the Cider Route}

Following the dissemination of the results from Step 1, the regional tourism association has decided to take the lead in undertaking Step 2. Thus, Step 2 defines a currently ongoing process for the collaborative design and development of a mission, vision, and strategy aimed at developing tools for the Cider Route such as a mobile application.

This mobile application would help visitors plan a visit, choose a particular route, and participate in activities (e.g., interesting stops, main attractions, complementary activities, restaurants, and hotels) along the Cider Route using their mobile phones. For example, cideries could be geolocalized and a wide range of useful information about them could readily be made available (e.g., opening hours, tastings, types of ciders available for purchase, history of the location, complementary activities such as apple picking, and tours of the cider production unit) (Panahi et al., 2013).

It is also fundamental to consider that the conceptualization and development of a mobile application as a boundary object would allow stakeholders to collaborate as part of a coherent, cohesive group working together to meet a shared objective (Worley et al., 2010). When stakeholders engage in such a process, they are likely to produce different artifacts in the process, including intermediate, IT, and non-IT artifacts. These artifacts are means to engage, reinforce, enrich, and develop stakeholder collaboration in the design and development of the mobile application.
However, the design and development of a mobile application involve a set of steps that would mobilize diverse expertise, knowledge elicitation, and sensemaking techniques and methods, which could also include other types of boundary objects supporting the cognitive involvement of participating stakeholders (Healey et al., 2015). For example, Carlile (2002) states that, in the case of new product or process developments, categories of boundary objects include "repositories (i.e., cost databases, parts libraries, etc.)", "standardized forms and methods", "objects and models", and "maps of boundaries".

In addition, the initial step in the design and development process would be based on a vision, mission, and strategy that need to be determined to ensure the longterm sustainability of the collaborative effort to rejuvenate the Cider Route. To achieve this objective, the group concept mapping approach is being employed. Group concept mapping is a participatory, bottom-up, collective means of involving a group of participants in an evaluation or strategic process (Kane \& Trochim, 2007). This approach makes use of the distributed knowledge (Rosas, 2016) of the participating stakeholders involved in the process, and has been used in various fields such as IT adoption and use, healthcare, and social program design (Cloutier \& Spooner, 2016; Rosas \& Kane, 2012). The group concept mapping approach is a mixed-methods approach that comprises six steps:

1. Preparation of the group concept mapping intervention with a steering committee

2. Idea generation about the vision, mission, and strategy during a group discussion leading to a list of action statements

3. Data structuring, which includes a contextual questionnaire to generate subgroup profiles, statement sorting to obtain a collective representation of individual representations, and statement rating on Likert-type scales to obtain perception measures (e.g., on the relative importance and feasibility of the action statements)

4. Concept mapping analysis (i.e., spatial and visual result preparation using concept map generation (i.e., multidimensional scaling analysis) (Kruskal \& Wish, 1978) and agglomerative hierarchical cluster analysis (i.e., Ward algorithm) (Everitt et al., 2011), and the production of matching patterns and strategic "go zones" for results visualization. This step should also include the production of an anchoring and bridging 


\section{Rejuvenating the Cider Route in Quebec: An Action Design Research Approach}

\section{Martin Cloutier, Laurent Renard, Sébastien Arcand, and E. Michael Laviolette}

index for the assessment of sorting consensus measures among participants, as well as internal reliability measures from the data.

5. Results appropriation by the group as part of a debriefing discussion. If conducted appropriately, this step could also contribute to the evaluation of the results' external validity.

\section{Knowledge mobilization, uptake, and use}

To sum up, the group concept mapping process begins within a collaborative group setting using qualitative data and information and also ends in a collaborative group setting. It produces the required qualitative and quantitative results and a clear renewed mission, vision, and strategy of the process moving forward.

Finally, the mobile application would help meet the needs of the Cider Route visitors. The stakeholders would have a tool that would help satisfy their needs for visit planning along the Cider Route by providing quality information on participating cideries. The mobile application also offers a "work around" for the Cider Route's ineligibility for the government program of signage for tourism theme trails and circuits. Although it will not have physical signs along the main route, visitors will instead benefit from enhanced virtual information. For example, the geolocalization of the cideries enables visitors to receive suggestions of specific itineraries linking them to one another.

Moreover, for the cideries participating in the Cider Route, the trips taken by visitors could be recorded by the application along with their assessment of their visits to the various sites. This will in return generate useful data to understand visitors' various needs and behaviours, which could be used to improve the proposed experience offerings and the customer experience at the cideries and on the Cider Route more generally. The functionalities of the mobile application would also be defined by conducting a second group concept mapping process, following the steps described above. However, this process would be strictly oriented toward the stakeholders' needs related to development of the mobile application, which could be integrated into the logic model.

For the Cider Route, this process would help define and fulfill the required vision, mission, and strategy. More concretely, the group concept mapping process produces a non-technological intermediate artifact, or a group representation, that is a concept map of its "in- ternal model" or cognitive system (Trochim \& Cabrera, 2005). This artifact can be restructured as a logic model for strategy design implementation with well-defined inputs, activities, outputs, outcomes, and impacts (markers for assessment) (Kagan et al., 2009; Yampolskaya et al., 2004).

\section{Conclusion}

One of the specific contributions of this article is to resolve a collaborative issue and build the capability to innovate among a group of stakeholders to rejuvenate the Cider Route. The action design research process enables the use of boundary objects as a means to induce collaboration among Cider Route stakeholders. Indeed, the work to be accomplished to create the Cider Route mobile application provides an ideal framework for redefining the route's mission, vision, and strategy using a bottom-up approach that will be integrative and create value for the stakeholders.

The lack of collaboration observed among stakeholders of the Cider Route in Quebec is not unique. For example, previous works have identified widespread collaboration issues in wine-related trails (Brás et al., 2010; Brunori \& Rossi, 2000). Aside from holding promise for addressing the collaboration challenges along the Cider Route, the action design research approach suggested in this article could be applied to other contexts in agrotourism, in particular, and in tourism more generally, by stimulating and supporting collective innovation processes.

As Step 2 of the research approaches its completion, it is also important to look ahead to Steps 3 and 4 of the action design research process. In Step 3 (reflecting and learning), the stakeholder group should think about and document the path they took to rejuvenate the Cider Route. This debriefing process would have important implications for the stakeholders in developing a sustainable way to maintain their collaboration and to capitalize on their achievement, thereby providing a means to respond to future needs and ongoing involvement. It would be important to list key success factors that would allow them to leverage the organizational learning points generated as part of the debriefing process. In Step 4 (formalization of learning), researchers need to identify the key success factors to mobilizing stakeholders in the collaborative process. Theoretical propositions could be generalized or adapted more formally as to address analogous situations for resolving widespread problems associated with collaborations in agrotourism trails. 


\section{Rejuvenating the Cider Route in Quebec: An Action Design Research Approach}

\section{Martin Cloutier, Laurent Renard, Sébastien Arcand, and E. Michael Laviolette}

\section{About the Authors}

L. Martin Cloutier is a Professor in the Department of Management and Technology in the School of Management at the University of Quebec at Montreal (UQAM), Canada. He holds a PhD degree from the University of Illinois at Urbana-Champaign, and received BSc and MSc degrees from McGill University in Montreal. He was the Master's Program Director in Management Information Systems from 2003 to 2016. His research program focuses on product, process, technological, and organizational innovation management; decision processes and tools for group decision making; mixed-methods research designs; and design science research. He has published thirty refereed articles, many on system-related management problems using system dynamics and group concept mapping. Professor Cloutier has initiated or led twenty group concept mapping projects in Canada and internationally in various areas including entrepreneurship, technological startups, continuous improvement, technology adoption and use, IT strategy design, and strategic development in cider and wine production.

Laurent Renard is a Professor in the Department of Management and Technology in the School of Management at the University of Quebec at Montreal (UQAM), Canada. He holds a PhD degree in Business Administration and a Master's degree in Sociology, both from the University of Quebec at Montreal (UQAM). He is currently the Master's Program Director in Information Technology in the School of Management UQAM. His research program focuses on e-tourism and strategy; IT strategic management; business analysis; and design science research. He has some twenty publications including articles, book chapters, and conference proceedings. He is also one of the editors of the book Les capacités de l'organisation en débat.
Sébastien Arcand is an Associate Professor and the Head of the Department of Management at HEC Montreal, Canada. His main teaching and publishing interests are in the area of cross-cultural management, socio-economic integration of immigrants, and the links between culture, identity, and entrepreneurship. Some of his teaching activities take place in Colombia. Besides his research and teaching activities, he works frequently with organizations helping them to build a strategic diversity management approach. He holds a PhD in Sociology from University of Montreal and is a Qualified Administrator for the Intercultural Development Inventory, a cross-cultural assessment of intercultural competence for individuals and organizations.

E. Michael Laviolette is a Professor of Entrepreneurship and Strategy at Toulouse Business School and an Associate Researcher at MAGELLAN-IAE in Lyon, France. He holds a doctorate degree and a post-doctorate certification for scientific direction (HDR) in Management, awarded at IAE-University of Lyon and ISEM-University of Montpellier, respectively. His research builds on resource-based, dynamic capabilities and network theories to analyze entrepreneurial and innovation processes within broader and diverse socio-economic systems. He has published several articles on spin-offs in SMEs, entrepreneurial skills and leadership development in incubators, entrepreneurial self-efficacy, and role models in educational programs, policy-based clusters as institutions. 


\section{Rejuvenating the Cider Route in Quebec: An Action Design Research Approach}

\section{Martin Cloutier, Laurent Renard, Sébastien Arcand, and E. Michael Laviolette}

\section{References}

Avenier, M.-J. 2010. Shaping a Constructivist View of Organizational Design Science. Organization Studies, 31(9-10): 1229-1255. http://dx.doi.org/10.1177/0170840610374395

Brás, J. M., Costa, C., \& Buhalis, D. 2010. Network Analysis and Wine Routes: The Case of the Bairrada Wine Route. The Service Industries Journal, 30(10): 1621-1641.

http://dx.doi.org/10.1080/02642060903580706

Brunori, G., \& Rossi, A. 2000. Synergy and Coherence through Collective Action: Some Insights from Wine Routes in Tuscany. Sociologia Ruralis, 40(4): 409-423.

http://dx.doi.org/10.1111/1467-9523.00157

Carlile, P. R. 2002. A Pragmatic View of Knowledge and Boundaries: Boundary Objects in New Product Development. Organization Science, 13(4): 442-455. http://dx.doi.org/10.1287/orsc.13.4.442.2953

Cloutier, L. M., \& Spooner, M.-P. 2016. Closing Gaps in Professional Service Delivery Processes: A Mixed Method-Based Analysis of Clinical Research Project Budget Management. In C. DiMauro, A. Ancarani, \& G. Vastag (Eds.), Research in the Decision Sciences for the Service Economy: Best Papers from the 2015 Annual Conference European Decision Sciences Institute: 32-52. New York: Pearson Inc.

Correia, L., Passo Ascençao, M. J., \& Charters, S. M. 2004. Wine Routes in Portugal: A Case Study of the Bairrada Wine Route. Journal of Wine Research, 15(1): 15-25. http://dx.doi.org/10.1080/0957126042000300290

Dumoulin, J. 2003. Les Routes Touristiques au Québec: De la Conception à la Signalisation. Téoros, 22(2): 34-40.

Everitt, B. S., Landau, S., Leese, M., \& Stahl, D. 2011. Cluster Analysis, 5th Edition. Chichester, UK: John Wiley \& Sons.

Gregor, S., \& Hevner, A. R. 2013. Positioning and Presenting Design Science Research for Maximum Impact. MIS Quarterly, 37(2): 337-355.

Gregor, S., \& Jones, D. 2007. The Anatomy of a Design Theory. Journal of the Association for Information Systems, 8(5): 312-335.

Hashimoto, A., \& Telfer, D. J. 2008. Positioning an Emerging Wine Route in the Niagara Region. Journal of Travel \& Tourism Marketing, 14 (3-4), 61-76.

http://dx.doi.org/10.1300/J073v14n03_04

Healey, M.P., Hodgkinson, G. P., Whittington, R., \& Johnson, G. 2015. Off to Plan or Out to Lunch? Relationships Between Design Characteristics and Outcomes of Strategy Workshops. British Journal of Management, 26 (3), 507-528. http://dx.doi.org/10.1111/1467-8551.12038

Hevner, A., \& Chatterjee, S. 2010. Design Research in Information Systems. Boston, MA: Springer US. http://dx.doi.org/10.1007/978-1-4419-5653-8

Iorio, J., \& Taylor, J. E. 2014. Boundary Object Efficacy: The Mediating Role of Boundary Objects on Task Conflict in Global Virtual Project Networks. International Journal of Project Management, 32(1): $7-17$.

http://dx.doi.org/10.1016/j.ijproman.2013.04.001

Johannesson, P., \& Perjons, E. 2014. An Introduction to Design Science. Cham, Switzerland: Springer International Publishing. http://dx.doi.org/10.1007/978-3-319-10632-8
Jolicœur, C. 2013. The New Cider Maker's Handbook. White River Junction, VT: Chelsea Green Publishing.

Kagan, J. M., Kane, M., Quinlan, K. M., Rosas, S., \& Trochim, W. M. K. 2009. Developing a Conceptual Framework for an Evaluation System for the NIAID HIV/AIDS Clinical Trials Networks. Health Research Policy and Systems, 7: 12. http://dx.doi.org/10.1186/1478-4505-7-12

Kane, M., \& Trochim, W. M. K. 2007. Concept Mapping for Planning and Evaluation. Thousand Oaks, CA: Sage Publications.

Kruskal, J. B., \& Wish, M. 1978. Multidimensional Scaling. Beverly Hills, CA: Sage Publications.

Le Moigne, J.-L. 1994. La Théorie du Système Général: Théorie de la Modélisation. Paris: Presses universitaires de France.

López Guzmán, T., Rodríguez García, J., \& Vieira-Rodriguez, A. 2014. Analysis of the Tourist Profile on the Sherry Wine Route, Spain. Journal of Tourism Challenges and Trends, 7(2): 9-26.

March, S. T., \& Smith, G. F. 1995. Design and Natural Science Research on Information Technology. Decision Support Systems, 15(4): 251-266.

http://dx.doi.org/10.1016/0167-9236(94)00041-2

Neuhofer, B., Buhalis, D., \& Ladkin, A. 2015. Technology as a Catalyst of Change: Enablers and Barriers of the Tourist Experience and Their Consequences. In I. Tussyadiah \& A. Inversini (Eds.), Information and Communication Technologies in Tourism 2015: 789-802. Cham, Switzerland: Springer International Publishing.

Orlikowski, W. J., \& Iacono, S. C. 2001. Research Commentary: Desperately Seeking the "IT" in IT Research - A Call to Theorizing the IT Artifact. Information Systems Research, 12(2): 121-134. http://dx.doi.org/10.1287/isre.12.2.121.9700

Panahi, M. S., Woods, P., \& Thwaites, H. 2013. Designing and Developing a Location-Based Mobile Tourism Application by Using Cloud-Based Platform. Presented at the 2013 International Conference on Technology, Informatics, Management, Engineering \& Environment (TIME-E), IEEE, June 23-26, 2013. http://dx.doi.org/10.1109/TIME-E.2013.6611982

Peffers, K., Tuunanen, T., Rothenberger, M., \& Chatterjee, S. 2007. A Design Science Research Methodology for Information Systems Research. Journal of Management Information Systems, 24(3): 45-77. http://dx.doi.org/10.2753/MIS0742-1222240302

Peris-Ortiz, M., de la Cruz Del Río Rama, M., \& Rueda-Armengot, C. (Eds.). 2016. Wine and Tourism: A Strategic Segment for Sustainable Economic Development. New York: Springer.

Rainer, G. 2016. Constructing Globalized Spaces of Tourism and Leisure: Political Ecologies of the Salta Wine Route (NWArgentina). Journal of Rural Studies, 43: 104-117. http://dx.doi.org/10.1016/j.jrurstud.2015.11.007

Rasmussen, S. L., Jensen, S., \& Lyng, K. M. 2013. Clinical Simulation as a Boundary Object in Design of Health IT-Systems. In M.-C. Beuscart-Zéphir, M. Jaspers, C. Kuziemsky, C. Nøhr, \& J. Aarts (Eds.), Context Sensitive Health Informatics: Human and Sociotechnical Approaches: 173-178. http://dx.doi.org/10.3233/978-1-61499-293-6-173

Rosas, S. R. 2016. Group Concept Mapping Methodology: Toward an Epistemology of Group Conceptualization, Complexity, and Emergence. Quality and Quantity, 2016: 1-14. http://dx.doi.org/10.1007/s11135-016-0340-3 


\section{Rejuvenating the Cider Route in Quebec: An Action Design Research Approach}

\section{Martin Cloutier, Laurent Renard, Sébastien Arcand, and E. Michael Laviolette}

Rosas, S. R., \& Kane, M. 2012. Quality and Rigor of the Concept Mapping Methodology: A Pooled Study Analysis. Evaluation and Program Planning, 35(2): 236-245.

http://dx.doi.org/10.1016/j.evalprogplan.2011.10.003

Sein, M. K., Henfridsson, O., Purao, S., Rossi, M., \& Lindgren, R. 2011. Action Design Research. MIS Quarterly, 35(1): 37-56.

Simon, H. A. 1996. The Sciences of the Artificial. Cambridge, MA: MIT Press.

Smith, N. C., Drumwright, M. E., \& Gentile, M. C. 2010. The New Marketing Myopia. Journal of Public Policy \& Marketing, 29(1): $4-11$.

http://dx.doi.org/10.1509/jppm.29.1.4

Star, S. L., \& Griesemer, J. R. 1989. Institutional Ecology, "Translations" and Boundary Objects: Amateurs and Professionals in Berkeley's Museum of Vertebrate Zoology, 1907-39. Social Studies of Science, 19(3): 387-420. http://dx.doi.org/10.1177/030631289019003001

Strauss, A. L. 1978. A Social World Perspective. Studies in Symbolic Interaction, 1: 119-128.

Takeda, H., Veerkamp, P., Tomiyama, T., \& Yoshikawa, H. 1990. Modeling Design Processes. AI Magazine, 11(4): 37-12. http://dx.doi.org/10.1609/aimag.vlli4.855

Telfer, D. J. 2001. Strategic Alliances along the Niagara Wine Route. Tourism Management, 22(1): 21-30.

http://dx.doi.org/10.1016/S0261-5177(00)00033-9
Trochim, W. M. K., \& Cabrera, D. 2005. The Complexity of Concept Mapping for Policy Analysis. Emergence: Complexity and Organization, 7(1): 11-22.

van Aken, J. E. 2005. Valid Knowledge for the Professional Design of Large and Complex Design Processes. Design Studies, 26(4): 379-404.

http://dx.doi.org/10.1016/j.destud.2004.11.004

Wang, D., Park, S., \& Fesenmaier, D. R. 2012. The Role of Smartphones in Mediating the Touristic Experience. Journal of Travel Research, 51(4): 371-387. http://dx.doi.org/10.1177/0047287511426341

Wang, D., Xiang, Z., \& Fesenmaier, D. R. 2016. Smartphone Use in Everyday Life and Travel. Journal of Travel Research, 55(1): 52-63. http://dx.doi.org/10.1177/0047287514535847

Worley, C. G., Feyerherm, A. E., \& Knudsen, D. 2010. Building a Collaboration Capability for Sustainability. Organizational Dynamics, 39(4): 325-334. http://dx.doi.org/10.1016/j.orgdyn.2010.07.004

Yampolskaya, S., Nesman, T. M., Hernandez, M., \& Koch, D. 2004. Using Concept Mapping to Develop a Logic Model and Articulate a Program Theory: A Case Example. American Journal of Evaluation, 25(2): 191-207.

http://dx.doi.org/10.1177/109821400402500204

Citation: Cloutier, L. M., Renard, L., Arcand, S., \& Laviolette, E. M. 2016. Rejuvenating the Cider Route in Quebec: An Action Design Research Approach to Stakeholder Collaboration and Innovation. Technology Innovation Management Review, 6(11): 6-17. http://timreview.ca/article/1030

Keywords: Cider Route, action design research, boundary object, agrotourism, stakeholder collaboration 